\title{
Reconsidering the role of language-in-education policies in multilingual higher education contexts ${ }^{1}$
}

\author{
Christa van der Walt \\ Department of Curriculum Studies, Stellenbosch University, South Africa \\ E-mail: cvdwalt@sun.ac.za
}

\begin{abstract}
As a result of transnational mobility of students and attempts to widen access to higher education, university campuses have become increasingly multilingual. Responses to this phenomenon have ranged from resistance (sticking to a local and established language) to wideranging attempts to become English-medium institutions. The fact that student populations can differ from one semester and one year to the next means that it becomes difficult to plan language-in-education strategies and practices. In the context of South African higher education, this paper argues that lecturers who teach multilingual classes cannot depend on policy makers to create circumstances in which deep learning will take place. It becomes necessary to think in terms of micro-planning (Baldauf 2006), or perhaps rather classroom strategies, to create spaces for multilingual learning.
\end{abstract}

Keywords: language policy, multilingual education, higher education

\section{Introduction}

Transnational mobility of students means that higher education classrooms are increasingly linguistically diverse. At the same time, higher education institutions are committed to widening access within national borders to minority groups, which may include linguistic minorities. In her description of the ultimate internationalised university, Roberts (2008:9) describes an institution that "is moving towards what we can call a more authentic internationalised university where multilingualism and lingua franca use are common, even normative and no one language has hegemonic power over the others". The question is, how could such a multilingual institution function? How can language be 'arranged' rather than 'policed' by means of a language-in-education policy (LEP)? If the linguistic composition of a class changes from one semester to the next, how can we plan teaching and learning optimally?

\footnotetext{
1 This article appeared as a chapter in the book Fremdsprachen in Studium und Lehre: Chancen und Herausforderungen für den Wissenserwerb, edited by A Knapp and K Aguado. Frankfurt: Peter Lang, pp 97-121. It is reproduced here with permission by the publisher and the editors.
} 
The focus in this paper is on the possibilities of acknowledging language as a local practice (Pennycook 2010). The idea of language as a local practice can be linked firstly to the core business of higher education, which is knowledge production, and secondly to situated classroom practice, in an effort to investigate the possibility of a framework for higher education institutions to move beyond implementing monolingual institutional language policies. This paper conceptualises languages in education as resources for classroom practice that requires expert training of academic staff, rather than expecting them to implement a topdown policy.

\section{Contextual factors}

The demands that higher education institutions face differ from one context to the next, and the differences between developed, developing, and underdeveloped countries are particularly noticeable. However, there are issues that have an impact on all higher education institutions, irrespective of their context. Although some institutions will be able to absorb the impact better than others, issues like internationalisation and education policies play a role in the management of institutions. Both of these issues are focused on in the discussion that follows.

\subsection{Higher education in a globalised world}

With prestigious institutions such as Harvard University considering a study-abroad period as compulsory to complete a degree (Tarrant 2010:434), higher education practitioners sharpen their focus on global citizenship by calling increasingly on higher education to facilitate and encourage student mobility. On the one hand, these initiatives are seen as giving institutions a competitive edge when it comes to developing international networks and student exchanges. However, international student mobility is also seen as generating income, because many universities use courses that require considerable financial investment from international students to fill gaps that have opened up due to a decrease in government funding. Moreover, international cooperation agreements as well as a neo-liberal agenda have led to the marketization of education, particularly at higher education level. A UNESCO Education Position Paper (2004) notes:

One of the issues which is generating an active and at times polarized debate is the liberalization and promotion of commercial trade of education services through trade agreements. The idea of academic mobility, students and scholars moving between countries is not new. However, the movement of students, education programmes and providers across borders for commercial and for-profit purposes is growing [...] There is concern that the decreasing state funding for higher education will decrease even further and that students will be targeted by private and often expensive providers which will further favour the rich and further disadvantage the poor

UNESCO Education Position Paper (2004:9)

The degree to which an institution can decide to ignore or neglect the pressure to 'internationalise' depends at least partially on the state of its finances, as the UNESCO paper makes all too clear. Making courses attractive for international students is seen as one of the most important indicators of an institution's competitiveness. Marginson and Van der Wende (2007:5) point out that "[f]or certain institutions, especially in the English-speaking world, international operations have become the primary mode of development". However, 
internationalising a campus can have benefits beyond the financial. Urban and Palmer (2014:308) indicate the potential of international students as an academic resource for the whole institution: "students must expand their intercultural and international knowledge to function in a diverse world, understand the international dimension of their disciplines, and build critical thinking skills". In discussing the reasons for transnational student mobility, Foster (2013:151) mentions a number of 'push' and 'pull' factors, noting that "[a] further powerful factor is the extent of students' awareness of the connection between language improvement and enhanced cross-cultural competency resulting in opportunities for better employment, which contributes to their readiness for participation in study abroad".

Despite the focus on intercultural or cross-cultural competence and the implied language proficiency to develop such competence, the language that has the status as the international language of science, English, is often used as an indicator of the degree to which a higher education institution has an 'international' character (Van der Walt 2013:70). The position of English as the language of transnational mobility is uncontested, and its prestige is supported by institutions that aspire to an internationalised campus. Lillis and Curry (2010:1) call English "the default language of Science and academic research and dissemination", noting that it is "considered by prestigious institutions to be the "global language of Science"".

In this context, language practitioners feel the need to develop mechanisms to solve the 'problem' of students who lack English-language proficiency by requiring a specific score on access tests, or by making courses in academic literacy or English for academic purposes compulsory. At the same time, policy makers develop an LEP that mandates the use of English as the only 'medium' of instruction or the language of learning and teaching (LoLT), usually starting at postgraduate level, as universities in the Netherlands have started to do.

In a development that runs parallel to the so-called internationalisation of higher education, institutions are asked to increase access to higher education by actively recruiting domestic students from minoritised groups, also referred to as the process of "massification". Such students may also use a minoritised language at home. In South Africa, the majority of higher education students speak a language that is not used in educational contexts beyond the first three or four years of schooling. However, African languages are spoken at home and appear in print, on the radio, and on television. This is the case in most parts of Africa, where English or French is then used as an LoLT. A similar situation exists in the USA, where a substantial number of students use Spanish, Mandarin or Korean (among others) at home. If students with these language backgrounds do not score well on access tests or on school exit examinations, they are required to attend additional language courses at higher education level. The mushrooming academic literacy industry is evidence of the perceived need for such courses. In countries like South Africa, calls for internationalisation cannot drown out the call for widening access to higher education for minoritised students. Despite the perception that English as an LoLT can fulfil both these roles, the low rate of participation and completion of both domestic (Scott 2009:25) and international students (Schumann 2008:47) shows that this simplistic view of LEP cannot be entertained any longer.

\subsection{A view of education policy as an instrument of reform}

In view of these circumstances, particularly regarding the important role of language in academic success, it becomes necessary to think beyond monolingual policies by accepting the 
situation where, firstly, a number of academic languages are jostling for position; and secondly, the number and variety of academic languages changes from one semester to the next. If one were to argue for bi-/multilingual education, such an educational setting would render any macro policy-making impossible. The radical alternative would be to have no LEP and leave decision-making to academics and students. To any administrator or manager, such linguistic laissez-faire would probably appear unthinkable and impossible. However, could we not conceptualise a situation where languages are merely part of a variety of academic resources that need a form of language management, as Spolsky (2004a) notes, rather than a language policy? Such an exercise requires a closer look at the nature of policy and the assumptions that underlie it.

Policy-making in education is a well-established field, where the development of policies and their role in bringing about educational change have been debated extensively since the second half of the previous century. Drawing on Foucault's discussions of power, Ball (1995:23) points out that "policy as discourse may have the effect of redistributing 'voice', so that it does not matter what some people say or think, and only certain voices can be heard as meaningful or authoritative". The role of policy as a centralised and coercive mechanism of control is obvious. However, in education systems all over the world, policies and curricula (one of the incarnations of policy) are accepted as inevitable, whether they are perceived as good or disastrous.

The process of policy development and implementation is multi-faceted and complex. In Ball's (1995:18) words, "[p]olicies pose problems to their subjects, problems that must be solved in context". This means that a policy is re-invented in each of a myriad of circumstances, so that just as there cannot be one authoritative reading of a text, there cannot be one authoritative implementation of a policy. The 'Yes, but what if ...' question inevitably leads to adaptations and unique interpretations of how a policy should be implemented. This process is not simple: Given constraints, circumstances, and practicalities, the translation of the crude, abstract simplicities of policy texts into interactive and sustainable practices of some sort involves productive thought, invention, and adaptation (Ball 1995:19).

The way in which top-down policy is realised at different levels has led to Baldauf (2006) identifying the need for micro language-planning for local contexts. This view resonates with that of Darling-Hammond (1998:642), who argues that we need a new framework that will enable us to think beyond policies that prescribe behaviours within particular boundaries, and to move towards processes that support teachers and students in solving the complex problems of the $21^{\text {st }}$ century; what she calls a "changed mission for education". Based on the work by Glaser (1990), who calls for changes in education based on rapidly diversifying school populations, Darling-Hammond (1998:643) calls attention not only to diverse student populations, but also to continuing changes in school contexts that require the productive thought, invention, and adaptation mentioned above.

Referring to the different points from which LEP can be initiated (from a central government or from local institutions), Shohamy (2006:76) argues that whether it is imposed from above or demanded from below, "LEP is another mechanism through which ideology is meant to turn into practice or practice into ideology". Such a 'mechanism' is hardly surprising when one considers the role of language(s) in defining nations and delimiting nation states: we speak German in Germany and French in France, and immigrants to Germany need to learn German just as minorities in France need to learn French. 
According to Shohamy (2006:78), the teachers, lecturers, students, and administrators are the 'soldiers' or 'servants' of the system, who carry out orders by internalising the policy ideology and its agendas as expressed in the curriculum, in textbooks and other materials, and in the very perceptions of language. However, this fairly bleak view of policy implementation is only partly true, as Shohamy (2006:91) acknowledges; and a number of examples exist of how teachers and lecturers resist or undermine policies (Van der Walt 2013:127), as will be discussed later.

Language-in-education policy is one type of education policy that can serve the purpose of reform. In the South African context, various policies, from the Constitution to regional language policies, purport to be advancing multilingualism and lifting the status of African languages. By placing the power of determining the LEP for educational institutions in the hands of such institutions, it can be argued that the policy landscape gives much scope to institutions to formulate and implement their own policies. In practice, this means that the parents and teachers (in the case of schools) or language practitioners and (sometimes) students (in the case of higher education institutions) can formulate an LEP that is uniquely suited to that particular institution. However, we know that educational institutions do not focus solely on their students; nor are they immune to dominant ideologies. In effect, this means that parents and teachers accept dominant ideas about powerful languages, and demand policies that will confer such power on their children and learners, respectively. Despite the range of language options, English is generally seen in South Africa as the one and only opportunity for a good education.

Therefore, education policies as instruments of change do not have a particularly good track record; and Darling-Hammond (1998:652) argues that successful policy-making to engender change needs "to find the right balance between top-down and bottom-up decision making". Although it is not the purpose of this paper to show what the right balance might be for LEP, the argument is that the way in which we currently conceive of LEP is not productive for teaching and learning in multilingual contexts. If there is an imperative that is more powerful than demands for internationalisation or the massification of higher education, it is the throughput rate of students. Since all higher education institutions have to manage "the tensions between official policy, local policy and its [sic] (relatively) problematic enactment in routine assessments and teaching" (Roberts 2008:9), the effect of LEP on successful teaching and learning cannot be ignored. It seems important then to consider 'policy-making' or the development of local policies at 'local' levels to enhance teaching and learning in ways that realise the potential of different combinations of resources in each classroom.

\subsection{Micro policy development}

The idea of micro policy development at classroom level has been discussed extensively by Baldauf (2005, 2006; among others) as a critical response to top-down ('macro') policy development, which may not take into account the realities or attitudes of the groups at the implementational end of language policy and practice. He defines micro-planning as follows: 
By contrast, micro planning refers to cases where businesses, institutions, groups or individuals hold agency and create what can be recognised as a language policy and plan to utilise and develop their language resources; one that is not directly the result of some larger macro policy, but is a response to their own needs, their own 'language problems', their own requirement for language management.

Baldauf (2006:155)

Case studies of multilingual learning and teaching at university level (see section 3 below) are attempts to respond to local needs. In some cases (for example Batyi 2014 and Madiba 2014), micro-planning is aligned with institutional policies that are not implemented widely, which is what Batyi (2014:6) found when staff and students claimed to be unaware of the official multilingual policy at her institution in South Africa. In another case, the multilingual policy at a South African university is regarded with suspicion and scepticism (Parmegiani and Rudwick 2014:107). In both of these cases, the history of the country plays a role in rejection or ignorance of an LEP, with the use of African languages in education raising the spectre of the predemocracy education system; where the use of African languages in schools was meant to keep students in low-paying jobs. In such circumstances, policy-making must be far more nuanced and adaptable. A top-down policy, which is often of the one-size-fits-all kind, cannot meet the needs of specific groups of students, and does not give lecturers the opportunity to negotiate language use in formal lectures, seminars, tutorials, and informal group discussions.

With reference to case studies in which micro language-planning took place, Baldauf (2005:156) makes a statement that is relevant to South African and possibly to European higher education students: "Although most of the studies are evaluative and there is often the suggestion of some tension between the macro and the micro, there is little or no suggestion that micro-level policy should be developed or that planning should extend beyond what is required to implement macro policy". This is also the case in a recent publication (Van der Walt and Hibbert 2014), where a selection of multilingual teaching practices at higher education level is described. Beyond these scholarly case studies, each of which probably relates closely to a particular academic's research interest or a $\mathrm{PhD}$ research project, there is little to suggest that the micro-planning in a particular module would extend beyond it, or that the academics involved would play an active role at institutional level to disseminate their findings and revise the institution's LEP. A possible way in which to get beyond isolated cases of multilingual teaching and learning is to radically rethink the existence of LEP, and focus on strengthening the ability of lecturers to make micro-planning decisions to support the learning of their multilingual learners.

\section{A focus on local practice}

In an attempt to move away from institutional (and often monolingual) LEPs, we need to ask questions that focus our attention on the core business of higher education, which is an engagement with knowledge (Knapp 2014:12). At South African institutions, this is usually formulated as engagement in three areas: teaching, research, and community interaction. In many instances, it is possible to merge these three aspects by grounding them in local communities. In my own context, the professional development of student teachers could take place in local schools; where academics, student teachers and teachers collaborate to research literacy development as part of professional development. In this way, student teachers bring new ideas from university classrooms into real-life classrooms, teachers act as mentors but are 
also involved in trying out new practices, and academics get the opportunity to observe and research the effectiveness of interventions and new practices. Such enterprises deepen the involvement of higher education institutions in surrounding communities. However, as Scott (2000:7) points out, the local production of knowledge does not preclude collaboration internationally. He points to two new paradigms of knowledge production:

The first is the crucial importance of context, not simply in terms of the end uses of science; not only in terms of helping to define scientific problems and to select appropriate methodologies; but by redefining reliable knowledge as knowledge that is socially robust. The second is the proliferation of research communities: not only have advances in communication and information technologies enabled research collaboration to take place on a global scale, but these new communities also embrace socially distributed researchers.

I would like to argue that the emphasis on socially robust knowledge, produced by socially distributed researchers, must involve tapping into local knowledge as expressed in local languages. Thus, a multilingual view of teaching and learning in higher education is not only about improving throughput by acknowledging the languages that students bring to their academic study: it is ultimately about mining the unique knowledge embedded in each language. The argument for multilingual classroom practices as crucial for knowledge production, and therefore for the core business of higher education, is elaborated upon in two ways in the discussion that follows: firstly by looking at the view of language as an "additional cognitive resource" (Knapp 2014:4), and secondly by focusing on multilingual classroom practices.

\subsection{Language as a knowledge resource}

Ruiz's (1984) 20-year-old argument that language should be seen as a resource rather than a problem remains valid. However, the argument in this paper goes beyond exploiting the linguistic resources of a multilingual student body and the possible advantages of mediating academic content in local languages. The focus here is on what is regarded as valid knowledge, in the sense of the kind of knowledge that is regarded as noteworthy, even when it is contextbound. Lillis and Curry (2010) illustrate the way in which local knowledge is devalued when reviewers of international journals ask authors to demonstrate a link with international concerns, or when they are encouraged to move beyond their own context. The link between local language(s) and local knowledge is important to support learning, and to act as a bridge or a foil to knowledge presented in dominant languages.

However, convictions regarding dominant languages of learning and teaching are deep-seated, and they prevent lecturers and students from making full use of the resource of their home or community language(s). It is necessary, first of all, to convince higher education practitioners of the value of local languages for economic development. In his discussion of political motivations in language policy, Williams (2011:47) points out, with regard to African countries, that "there is no evidence to suggest that the use of exoglossic languages such as French and English have contributed to development in proportion to their excessive dominance in educational and other official domains". 
However, it is important, in the second place, to recognise the devastating effects on individuals' minds when they start talking about their own languages in the context of this 'excessive dominance'. Probyn (2001:258) quotes one of her research participants, a history teacher, saying that the perceived "lack of subject terminology in the students' mother tongue made them feel '... you have not had any contribution to civilisation"'. Small wonder then that he (the teacher) continues, "You would find that education is alienating for the students ... or even myself". Of course, language is one of many factors that play a role in students feeling disenfranchised, and yet it is a powerful indicator of identity and status. Mastery of a dominant language opens doors for some, but unfortunately not for enough students. In global terms, the invisibility of the majority of the world's languages creates a skewed and biased picture of knowledge production, particularly in developing countries. In her concluding chapter for a UNESCO Forum on Higher Education, Research and Knowledge, Singh (2009:197) notes the strong feelings that emerged in the Forum discussions, questioning the possibility of this Forum creating a 'global' overview of knowledge systems without taking account of research published "in languages other than the mainstream languages of scientific communication and publication". I agree with Lillis and Curry (2010:161) that the Anglophone-centered ideologies and practices that position the rest of the world as the 'other' must be made visible. Furthermore, I would argue that these ideologies and practices should be countered by alternative views of "what counts as knowledge" (Lillis and Curry 2010:161).

Multilingual classrooms are spaces where different perspectives and ideas can flourish, and such classrooms become vibrant meaning-making spaces that should be lauded rather than upbraided for their 'mixture' of languages. In a discussion of the Sesotho terminology for celestial bodies, Leeuw (2014) argues that these names represent an alternative world view which provides evidence of indigenous "knowledge of persons, places, or things" (Horsthemke 2004:34). It is only through the use of this language that a different perspective, a different knowledge, emerges.

However, it does not make sense to ignore scientific publications in English - something that would be very difficult to do, in any case. In the same way that local knowledge is made available in local languages as well as in English, Lillis and Curry's research participants (2010:127) also argue for translating 'international' (i.e. English) texts into local languages to disseminate international research: "one compelling reason for her [the research participant] to write is also 'because of [university] students who don't read English, so it's writing something, articles, just for the students"'. In all these cases, the interaction of English and other languages is important for knowledge production.

\subsection{Local classroom practices}

A variety of multilingual classroom practices have been described in African as well as European and North American contexts. These include, among others, code-switching and colanguaging (Van der Walt 2013), the use of interpreters in the classroom (Van Rooyen 2005; Beukes and Pienaar 2006) and translanguaging (Madiba 2014; Makalela 2014). The purpose in this section is to point to their potential to act as examples of best practices.

I have argued (Van der Walt 2013:127) that '[a]s a result of the relative 'academic freedom' of HE [higher education] practitioners and the relative unpredictability of student population profiles from one year to the next, language in education policy implementation is often 
contingent and ad hoc, relying on lecturers' experience and their perception of students' ability to make meaning of their course materials and academic activities". Like teachers, lecturers remain aware of their students' ability to keep up (or not) with material presented to them in the LoLT. One of Probyn's (2001:260) research participants formulates this thought strikingly: " I'm just coming to their mother tongue so that they can gain confidence in what they are understanding up to this point... you want their cooperation, you negotiate their cooperation"' (my emphasis). Of course, this situation is ideal if the majority of the students share a language with the lecturer. When this is not the case, knowledge production can be jeopardised. Knapp (2014:7) discusses a number of cases where lecturers have to use English as an LoLT, with the result "that lecturers often are less spontaneous and less flexible in their language use, and speak more slowly than when lecturing in their L1". More alarmingly, however, students are less willing to ask questions when they have to use English (Airey 2011).

The formality of a lecture hall and the fact that it is a public space (in the sense that any student and perhaps lecturers can attend a lecture) means that the lecturer and students may feel exposed if an institutional LEP is monitored closely. Unless this situation is changed, lecturers and students may not be willing to risk 'adapting' such a policy to the needs of individual classes. Getting involved in institutional policy-making is a venture many academics may try to avoid, and there is much literature on how to develop and revise institutional LEPs. My concern here is more with situations where there is room to move, and where the lecturer may be able to create space for multilingual teaching and learning.

Using a home or community language to 'negotiate' students' participation may not work if students are not prepared for such practices. Doing a survey of language use and attitudes should be a first step, since many students (and lecturers) subscribe to the myth that languages need to be kept strictly apart, even when one of them has been used at school level or to discuss work with fellow students. The separation between the language used at home and the LoLT is usually defended for one or both of the following reasons, both of which have been discredited:

- $\quad$ One learns a language faster when the home language does not 'interfere' (see Cummins (1979) for a counter argument).

- There is no subject terminology for the home language (see Ramani et al. (2007) for subject-specific terminology development, and Madiba (2014) for the development of glossaries in African languages).

In the case of African languages, and possibly other minoritised languages, the idea of languages first having to 'develop' before they are useful for teaching and learning is at best a diversionary tactic; since any kind of discussion, even when much code-switching takes place, can facilitate learning. However, students' perceptions of and attitudes towards the use of minoritised languages in higher education can stymie attempts to use them. This was Ngcobo's (2014:134) experience when he used a questionnaire to determine students' attitudes towards English and their home language in higher education. He reveals that " $t]$ he students' responses to the first questionnaire displayed a preference for the informal use of their L1 as a learning resource, but this did not initially translate into positive attitudes concerning the formal use of their L1 in higher education". Even if students do not accept code-switching to a local language initially, Ngcobo shows that they can be convinced when responsible code-switching and controlled co-languaging activities are introduced, and when academic English is affirmed and 
strengthened by using the local language. As a result, student attitudes change; and this creates the impetus for more multilingual classroom practices.

When the context allows it, and when students seem amenable to the introduction of home or community languages in the class, their use can be planned by introducing a topic in such a language, by providing glossaries and multilingual notes, and by creating space for multilingual discussions. Whereas an LEP can constrain language choices in formal, lecture-hall situations, lecturers and students have more freedom in (relatively) informal situations, such as during group work and student-lecturer consultations. Such small-group and one-on-one discussions in other languages may break down negative attitudes towards the use of minoritised languages in higher education.

\section{Language management at higher education level: A learning and teaching issue}

From the discussions above, the agency of students and lecturers can be seen: they follow practices that support learning, irrespective of the language policy requirements. For that reason, it seems as if the 'language policy', or the management of language, needs to be located elsewhere. If students and lecturers make decisions based on the situation in a specific class for a specific semester, it seems logical that any kind of policy should focus on this decisionmaking process.

If we accept that the main purpose of higher education institutions is to work productively and creatively with knowledge, then policies should aim to support this purpose. Regulating the use of resources in a way that blocks the development of knowledge is counter-productive. In terms of the argument made in section 3.2, the languages that students bring to the classroom form part of the resources on which they can draw: some have the ability to type quite fast, some are able to use a tablet to take notes, others have access to an extended library at home, or to an older family member or friend who studied the same course and can offer advice. It would not occur to higher education managers to write a Home Library Policy or an Electronic Device Policy. Knowing and being able to draw on a variety of languages is no different. However, knowing how to do so effectively is a pedagogical issue which is often regulated: we know that electronic devices can support learning in specific ways. We teach students how to use books and articles for studying. Furthermore, we value independent learning; for example, you are not allowed to plagiarise from academic sources, or allow your more knowledgeable relative to write your test. Using a variety of languages effectively is a teaching and learning issue as well: this is where multilingual classroom practices find their 'regulative' home.

In her article where she discusses the role of policy in educational change, Darling-Hammond (1998:661) makes a point about schools, teachers, and policies that we can apply directly to the situation of multilingual higher education:

[E]ducational change in the context of current demands of schools requires substantially more knowledge directly in the hands of educators, rather than organized to influence the top of a hierarchical system from which it is supposed to 'trickle down' to teachers in the form of memos, directives, texts, and curriculum guides.

What I am arguing for in this paper is not to simply reverse this 'flow', but to remove decisions about language use in higher education classrooms from discussions about policy to a much 
broader concern for effective teaching and learning. What that means is that we place the responsibility for language arrangements in the hands of the lecturers so that these language arrangements become part of the decision-making processes when planning the teaching programme for a particular class. This is in line with Tierney's (2008:158) description of higher education institutions: "Increasingly, what one finds in organisational life is a more nuanced sense of decision making that may well serve the needs of academic governance in the $21^{\text {st }}$ century". To build the capacity for such decision-making would mean structured and sustained academic staff development that goes further than institutional pressure to improve fluency in English (important as that may be). The next section is an attempt to provide a framework for developing awareness and collecting information to make decisions and construct activities in multilingual classrooms, using the languages that students bring to the classroom as a learning resource.

\section{Moving towards classroom decision-making rather than LEP}

Baldauf (2006:153) distinguishes between macro and micro elements of social communication by describing the micro as focusing on "processes, relations and dynamic activities" rather than "fixed objects or structures" (the macro elements). This view of micro elements fits the contingent nature of classroom decision-making particularly well, because micro-planning of language use will be an on-going and dynamic process, rather than a once-off decision that would govern all interaction in the classroom irrespective of the students, the course, or the materials. As Knapp (2014:12) points out,

$\ldots$ the texts and discourses that are typical of university communication ... are not necessarily performed in the same language as the official teaching-learning discourse in lectures and seminars, but, to different degrees, offer options for choosing other/additional languages instead, in some cases including the possibility of codeswitching within such discourses or texts.

She (Knapp 2014:8, 9) presents an example of classroom discourse (at a German university) that shows the intricacy and contingency of language use in a higher education classroom:

\section{Example from an Applied Chemistry class: Chelate cycle}

1. L: Does anybody know chelate cycle? (- -) Chelate cycle, who knows what that is? $(---)$

2. L: Doesn't anybody speak Greek or Latin?

3. Ss: (laughter) No, no.

4. L: Still nobody.

5. Ss: (trying to repeat the word) Kilots? Kilos?

6. L: (to the only student with English as L1) What is Krebs?

7. S1 (US): Crabs.

8. L: Crabs?

9. S1 (US): Crab or a lobster.

10. L: You know this animal with eight legs. Which animal has also eight legs?

11. Ss: Spider.

12. S2 (Macedonia) Aaah, Chelots!

13. L: Yes, which language is this? 
14. S2: This language is Macedonian. We are on a border with Greece.

15. L: I use the English pronunciation of chelates (/'ki:leits/.) (writes word on the board)

16. S3 (China): Tschelos?

17. Ss and L: (laughter)

18. L: We don't care about pronunciation (describes the similarity between the chemical procedure and a crab, trying to grasp food with its claw). It has a claw finger. There are elements. The claw picks one element. It is selective. This is the chelate cycle. Chelat-Ring auf Deutsch. This here is phenanthroline. (Describes phenanthroline and chelate cycle)

19. Ss: (nodding; one students makes grasping movements with his hands) Mmhmm, mmhmm.

As is clear from this extract, the lecturer did not know that one of the students had a language background that would help with the understanding of a Greek word. S/he could possibly have capitalised more on the Macedonian student's knowledge (for example, by asking for a translation), but it is important that the student was able to make the link with his/her home language. The lecturer also capitalises on the bilingualism of a native speaker of English who seems to know German (turn 6); and code-switches to German (turn 18), probably for the German students' benefit.

In the next example, we see a more consistent pattern of code-switching between Afrikaans and English, in this case during a lecture to a large class of first-year geology students. The language arrangement in this case is known as the "T-option" (for tweetaligheid, meaning 'bilingual'), where lecturers are expected to code-switch between English and Afrikaans and provide learning material in both languages. Students can choose either of these languages for classroom communication, assignments, and tests. In the text below, the Afrikaans is indicated in italics, with my own translation in square brackets. Each switch is numbered.

\section{Example from a Geology class}

1. Julle ken alreeds die rotssiklus. [You already know the rock cycle.]

2. I'm not going to ask you again to keep quiet, please. Thank you. Igneous rock forms when molten rock cools and crystalizes. So any rock that forms due to the crystallization of magma is called igneous rock.

3. 'n Stollingsgesteente. Die magma kom van die mantel en van die kors omdat ons gedeeltelike smelting van soliede rots kry. Die magma is minder dig as die gesteentes rondom. [Igneous rock. The magma originates in the mantle and from the crust because we have partial melting of solid rock. The magma is not as dense as the rocks around it.]

4. So the magma has to work its way upward to the surface where it can produce a volcanic eruption.

5. [Later in the same lecture: the lecturer holds up different rocks to explain differences.]

6. So, this we would also say of a light-coloured rock because it has touches, large crystals of a light-coloured mineral. That would be a darker-coloured rock so this one would contain more iron and magnesium in this one than that one. Here is our one exception: It looks like glass, it is volcanic glass. And it is called obsidian.

7. Obsidiaan. 
8. And, it is literally glass that shoots out of the volcano but the composition is riolythic.

9. En van julle sal onthou dat 'n Riolitiese magma het baie $\mathrm{FEO}_{2}$, partykeer $70 \%$. [Some of you will remember that a riolythic magma consists of large quantities of $\mathrm{FEO}_{2}$, up to $70 \%$.]

10. So, this is the one exception. Obsidian is dark in color but it has a low iron content. Low iron and magnesium. The only reason it's black is because it crystallizes so quickly. It comes out of it, [...] basically squirts. It's like throwing ice cold water on something really hot so you make it intricately form a glass and the crystal has no time to form so there's no crystal plane to reflect light or anything. So, sorry it looks dark. High $\mathrm{FEO}_{2}$, low iron. Okay. So, that's your obsidian, so now you know another volcanic rock. What would you call that? That's the granite. You've seen it before.

11. Dis 'n tipiese graniet. Hy't wit stukkies en hy't donker stukkies. [This is a typical piece of granite. It has white bits and dark bits.]

Although the code-switching is provided for in the language policy and plan, there is no research on the most effective kind of code-switching. This is not the kind of information that would be included in an LEP, either. In the example above, the lecturer uses responsible codeswitching both ways (Van der Walt, Mabule and De Beer 2001:177; García 2009:298); ensuring that key terms are provided in both languages, with switches from English to Afrikaans (turns 6 and 7) and from Afrikaans to English (turns 9 and 10). This means that academic literacy is developed in both languages.

These two kinds of instructional language use cannot be accounted for in a prescriptive LEP context. An LEP would also not give an account of the way in which good teaching is intricately linked to language use that is effective for learning; for example, engaging students in the discussion to make meaning (in the first example), and building biliterate academic proficiency (in the second example). In both of these cases, lecturers make almost instinctive decisions about the alternate use of languages, and extensive research is required to evaluate the effectiveness of these strategies for learning.

The process of constructing guidelines for classroom decision-making, particularly in terms of using more than one academic language, needs to consider the extent to which lecturers may feel constrained by an existing LEP and by institutional culture. If there is room to include other languages in the classroom, the following steps would have to precede the planning of multilingual support and collaboration in lectures and assignments:

- $\quad$ a survey of the academic language profile for a particular semester;

- $\quad$ the language competencies of the lecturer and the students;

- a discussion about students' expectations regarding the use of a dominant language for lectures, group work, and assessment.

As pointed out in the first item on the list, knowing the language profile of a group can guide the lecturer when discussing particular concepts and terms, both to explain as well as to contrast terms from different languages. Airey (2009:109) urges lecturers to "[d]iscuss the fact that there are differences when lectures are in a second language", and to do so at the start of a course, even when there is no institutional space to include other languages in the classroom. 
In her book English for Law, Riley (1994:1) contrasts the different terms from major European languages; pointing out words that look alike, but that have different meanings in the different legal systems. I am not suggesting that a lecturer in biochemistry or geology should necessarily know such terms in different languages: the point is that allowing students to contrast and compare certain terms from their own (language) background can deepen knowledge and prevent misunderstanding.

The English-language competence of the lecturer and the students is often mentioned as a problem in transnational education (see the second point in the bulleted list). Students are expected to have a particular score on tests such as the International English Language Testing System (IELTS), or on the Common European Framework of Reference for Languages (CEFR). Lecturers' proficiency in English has been the focus of a number of studies (see Knapp 2014:7), and a lack of proficiency may even be blamed for students not doing well or not understanding the content (Van der Walt 2006:366). If the lecturer shares a language with some of the students, this can be used to provide translations; as Knapp's example above shows. Even receptive ability in another classroom language - what Airey (2009:110) calls "interpretive" ability - can act as a comprehension check, when lecturers ask students to repeat or ask a question in that language. Having the ability to understand their language, even when the lecturer cannot respond in it, can act as an accommodating device. The same goes for students when they participate in discussions: if they can follow in one language and produce work in English, communication can take place. When the lecturer does not understand a language at all, a request for translation to English is not only necessary, but also supportive of learning.

The degree to which students' languages (other than the LoLT) have been used at secondary school level is also an indication that these languages may be available for academic purposes. To ignore that fact would be wasteful, because, as Airey $(2009: 89,110)$ finds, the Swedish students in his study managed to develop bilingual scientific literacy by the time they reached their second year of instruction in English: clear proof of Cummins's Common Underlying Proficiency (CUP) hypothesis (Cummins 1979), which posits that concepts learnt in Swedish are available fairly quickly in English.

The third point (from the bulleted list above) refers to the common perception that languages should be separated, and to the expectation that a so-called "international" course should be presented in English. A discussion about the role of other languages for learning and possible strategies to strengthen academic English could address fears that multilingual teaching and learning (judiciously done) will somehow 'interfere' with the acquisition of English for a particular academic field. This discussion, situated in the context of a particular time and place, emphasises the fact that language needs, expectations, and distribution are fleeting, but that "a discussion of language in place will open up an understanding of the interactive nature of our physical environment suggesting not so much that language happens in particular places, but rather that language use is part of a multi-faceted interplay between humans and the world" (Pennycook 2010:2).

When we use these three points as a survey, possible multilingual strategies can be developed. Let us take the classroom language survey below as an example. 
Table 1: Hypothetical classroom language survey for an international (English) programme

\begin{tabular}{|l|l|l|l|}
\hline Language profile & $\begin{array}{l}\text { Language } \\
\text { competence } \\
\text { lecturer }\end{array}$ & $\begin{array}{l}\text { Language } \\
\text { competence } \\
\text { students }\end{array}$ & $\begin{array}{l}\text { Language } \\
\text { expectations }\end{array}$ \\
\hline $\begin{array}{l}\text { Major and minor } \\
\text { language groups, 5 } \\
\text { from UK, 2 German, } \\
\text { 2 Polish (living in } \\
\text { Germany). }\end{array}$ & $\begin{array}{l}\text { English-German } \\
\text { bilingual } \\
\text { academically, } \\
\text { receptive French. }\end{array}$ & $\begin{array}{l}\text { Home language and } \\
\text { English bilingual } \\
\text { academically. Other } \\
\text { academic languages: } \\
\text { Russian, French. }\end{array}$ & $\begin{array}{l}\text { To learn English for } \\
\text { professional } \\
\text { purposes, to pass the } \\
\text { course well. }\end{array}$ \\
\hline
\end{tabular}

I admit to having devised a very neat example, but this is merely to illustrate a possible process whereby multilingual spaces can be opened up (Hornberger 2009). When we take this example as a starting point, the existence of academic literacies in other languages is a foregone conclusion. Resources (e.g. textbooks, web-based materials, dictionaries) are available. On a very basic level, the lecturer can refer students to such materials. A next step could be to encourage students who share academic languages to discuss lecturer-generated problems in language groups. If students cannot be grouped in that way, they can be encouraged to develop $\mathrm{bi}$-/multilingual word lists. These actions encourage participation and mitigate one of the problems of learning and teaching in English, which is that "students may make fewer contributions (e.g., suggestions, critical comments) and may experience fewer opportunities to display knowledge and check understanding" (Knapp 2014:8). In terms of classroom decisionmaking, these strategies can be planned and structured as part of preparing the course for the semester.

These multilingual strategies are probably used by students whether the lecturers encourage them or not, as my own research has shown (Van der Walt and Dornbrack 2011). However, acknowledging and supporting them in class sends a powerful message about other academic languages as resources. A next step would be for the lecturer to make other languages more visible by using them in class. In the example above, the lecturer's knowledge of French, even though it is only receptive, is enough to check on comprehension. Knowledge of German and English can be exploited by code-switching responsibly (Van der Walt, Mabule and De Beer 2001:130), which means that the lecturer focuses on concepts and terminology in both languages. This kind of code-switching is different from conversational code-switching; which can be more random, in the sense that it does not focus on an equal weighting of key words in both languages. It is at this point that the fluidity of classroom conversations may complicate decisions about language use. The lecturer's awareness of possible misunderstanding among students would have to be sharpened, so that s/he can provide translations or brief explanations in another language, should it be necessary.

The process that I have just described assumes that the course is presented primarily in English, and that other languages are used to support learning and teaching in English. This is what García (2009:297) calls "flexible convergence", where a variety of languages is used to produce assignments and tests in English. Acknowledging other languages by using them in teaching materials (alongside English, i.e. co-languaging) and by accepting student work in more than one language is known as "flexible multiplicity" (García 2009:310), which would lead to the development of academic biliteracy, or "bilingual scientific literacy", as Airey (2009:3) calls it. Since assessments (whether oral or written) are important as indicators of academic success, 
a particular arrangement would have to be formalised (in the form of a policy or faculty/departmental guidelines) to ensure that students are not penalised when they use a language other than the LoLT for assessment tasks. Since one of the students' expectations in Table 1 is to pass the course well, they may want to write in their home languages. Knapp (2011:56) notes that achieving good marks is often the reason that German students may not want to follow an international course in English. Similarly, Leask (2011) describes a situation where native speakers of English avoid international students because they want to make sure that the final outcome of a group assignment is not jeopardized by students who may not be able to use English very well. On the other hand, the way in which teaching and assessment are structured may encourage writing in English; for example, when students simply memorize and reproduce what is presented in English (see Knapp 2014). The pressure of assessment is one of the reasons that a biliterate approach (that is, flexible multiplicity) may be fairer to students (should lecturers have the resources to mark in more than one language).

What would be the role of languages that are not generally used for academic purposes? This is the case with African languages, despite various policies that have attempted to regulate their use in higher education. I would like to argue that they should be used, depending on student attitudes and the educational context. Let us look at an example again.

Table 2: Hypothetical classroom language survey for a South African (English) programme

\begin{tabular}{|l|l|l|l|}
\hline Language profile & $\begin{array}{l}\text { Language } \\
\text { competence } \\
\text { lecturer }\end{array}$ & $\begin{array}{l}\text { Language } \\
\text { competence } \\
\text { students }\end{array}$ & $\begin{array}{l}\text { Language } \\
\text { expectations }\end{array}$ \\
\hline $\begin{array}{l}\text { Major and minor } \\
\text { language groups, 5 } \\
\text { speaking isiZulu, 2 } \\
\begin{array}{l}\text { Setswana and 3 } \\
\text { English. }\end{array}\end{array}$ & English-speaking. & $\begin{array}{l}\text { Academic language } \\
\text { is English from } \\
\text { school level. }\end{array}$ & $\begin{array}{l}\text { To learn English for } \\
\text { professional } \\
\text { purposes, to pass the } \\
\text { course well. }\end{array}$ \\
\hline
\end{tabular}

In this case, "flexible convergence" (García 2009:297) seems to be the only option, since African languages are not generally seen in academic print materials or used for formal assessment activities. However, at least as far as reading in African languages is concerned, there are possibilities for "flexible multiplicity" (García 2009:310), as Ngcobo (2014) reports. He provided printed instructions for group work, using isiZulu instructions and prompts. As he points out (Ngcobo 2014:136), actual experience of using isiZulu in higher education classrooms changes student attitudes to this African language. Students' expectations were therefore ignored, which may be necessary if their understanding is improved by using a language that they perceive as suitable only for informal conversations.

\section{Conclusion}

Current conceptions of LEP place the focus on the institution, which may be necessary when it comes to deciding on the use of a language for administrative purposes, such as the language of notices, of communication, and of meetings. Yet even in these domains, an administrator who is addressed in a language of the community or region will use this language, whether it is the official language of the institution or not. 
Although language policy and planning and LEP have been productive fields of research for the past 70 years, the realities of $21^{\text {st }}$ century life have changed to the extent that both top-down and bottom-up attempts at policy-making are inadequate for our multilingual and changing classrooms. I agree with Spolsky (2004b:13) when he compares the management of language to Cnut trying to sweep back the waves, and this futile exercise has never been more obvious in the context of multilingual higher education. We have to think in different ways about managing multilingual classrooms to improve student performance.

\section{References}

Airey, J. 2009. Science, language and literacy: Case studies of learning in Swedish university physics. Uppsala: Uppsala University.

Airey, J. 2011. The relationship between teaching language and student learning in Swedish university physics. In B. Preisler, I. Klitgard and A. Fabricius (eds.) Language and learning in the international university. From English uniformity to diversity and hybridity. Bristol etc.: Multilingual Matters. pp. 3-18.

Baldauf Jr, R. B. 2005. Language planning and policy research: An overview. In E. Hinkel (ed.) Handbook of research in second language teaching and learning. Mahwah, NJ: Erlbaum. pp. 957-970.

Baldauf Jr, R. B. 2006. Rearticulating the case for micro language planning in a language ecology context. Current Issues in Language Planning 7(2-3): 147-170.

Ball, S. 1995. What is policy? Texts, trajectories and toolboxes. Buckingham: Open University Press.

Batyi, T. 2014. Development of tourism diploma, isiXhosa-speaking students' academic literacy: A multilingual intervention. Doctoral dissertation. Port Elizabeth: Nelson Mandela Metropolitan University.

Beukes, A-M. and M. Pienaar. 2006. Some factors influencing the use of simultaneous interpreting as an alternative to parallel-medium teaching in tertiary education. Journal for Language Teaching 40(2): 127-138.

Cummins, J. 1979. Linguistic interdependence and the educational development of bilingual children. Review of Educational Research 49(2): 222-251.

Darling-Hammond, L. 1998. Policy and change: Getting beyond bureaucracy. In A. Hargreaves, A. Lieberman, M. Fullan and D. Hopkins (eds.) International handbook of educational change. Dordrecht: Kluwer Academic. pp. 642-667.

Foster, M. 2013. Student destination choices in higher education: Exploring attitudes of Brazilian students to study in the United Kingdom. Journal of Research in International Education 13: 149-162. 
García, O. 2009. Bilingual education in the 21st century: A global perspective. Chichester: Wiley-Blackwell.

Glaser, R. 1990. Testing and assessment: O Tempora! O Mores! Pittsburgh, PA: University of Pittsburgh, Learning, Research and Development Centre.

Hornberger, N. 2009. Multilingual education policy and practice: Ten certainties (grounded in Indigenous experience). Language Teaching 42(2): 197-211.

Horsthemke, K. 2004. 'Indigenous knowledge' - conceptions and misconceptions. Journal of Education 32: 31-48.

Knapp, A. 2011. When comprehension is crucial: English as a medium of instruction at a German university. In A. De Houwer and A. Wilton (eds.) English in Europe today. Amsterdam and Philadelphia: John Benjamins. pp. 51-70.

Knapp, A. 2014. Language choice and the construction of knowledge in higher education. European Journal of Applied Linguistics 2(2): 1-39.

Leask, B. 2011. 'Beside me is an empty chair'. The student experience of internationalisation. In E. Jones (ed.) Internationalisation and the student voice. New York, NY: Routledge. pp. 317.

Leeuw, L. 2014. An exemplary astronomical lesson that could potentially show the benefits of multilingual content and language in higher education. In L. Hibbert and C. Van der Walt (eds.) Multilingual universities in South Africa. Bristol: Multilingual Matters. pp. 167-178.

Lillis, T. and M. Curry. 2010. Academic writing in a global context. London: Routledge.

Madiba, M. 2014. Promoting concept literacy through multilingual glossaries: A translanguaging approach. In L. Hibbert and C. Van der Walt (eds.) Multilingual universities in South Africa. Bristol: Multilingual Matters. pp. 68-87.

Makalela, L. 2014. Teaching indigenous African languages to speakers of other African languages: The effects of translanguaging for multilingual development. In L. Hibbert and C. Van der Walt (eds.) Multilingual universities in South Africa. Bristol: Multilingual Matters. pp. $88-104$

Marginson, S. and M. Van der Wende. 2007. Globalisation and higher education. (Education Working Paper No. 8). Paris: OECD Education Working Papers Series. Available online: http://doc.utwente.nl/60264/1/Marginson07globalisation.pdf.

Ngcobo, S. 2014. Dual language instruction: Its impact on attitudes towards the role of African languages in education. In L. Hibbert and C. Van der Walt (eds.) Multilingual universities in South Africa. Bristol: Multilingual Matters. pp. 123-144. 
Parmegiani, A. and S. Rudwick. 2014. isiZulu-English bilingualisation at the University of KwaZulu-Natal: An exploration of students' attitudes. In L. Hibbert and C. Van der Walt (eds.) Multilingual universities in South Africa. Bristol: Multilingual Matters. pp. 107-122.

Pennycook, A. 2010. Language as a local practice. London: Routledge.

Probyn, M. 2001. Teachers' voices: Teachers' reflections on learning and leaching through the medium of English as an additional language in South Africa. International Journal of Bilingual Education and Bilingualism 4(4): 249-266.

Ramani, E., T. Kekana, M. Modiba and M. Joseph. 2007. Terminology development versus concept development through discourse: Insights from a dual-medium BA degree. Southern African Linguistics and Applied Language Studies 25(2): 207-223.

Riley, A. 1994. English for law. Ismaning: Hueber.

Roberts, C. 2008. Introduction. In H. Haberland, J. Mortensen, A. Fabricius, B. Preisler, K. Risager and S. Kjaerbeck (eds.) Higher education in the global village. Roskilde: Roskilde University. pp. 7-15.

Ruiz, R. 1984. Orientations in language planning. NABE Journal 8(2): 15-34.

Schumann, A. 2008. Interkulturelle Fremdheitserfahrungen ausländischer Studierender an einer deutschen Universität. [Intercultural experiences of being foreign students at a German university]. In A. Schumann and A. Knapp (eds.) Mehrsprachigkeit und Multikulturalität im Studium [Multilingualism and Multiculturality in Academic Studies]. Frankfurt: Peter Lang pp. $30-45$.

Scott, P. 2000. Globalisation and higher education: Challenges for the 21st century. Journal of Studies in International Education 4(3): 3-10.

Scott, I. 2009. First year experience as terrain of failure or platform for development? In B.

Leibowitz, A. Van der Merwe and S. Van Schalkwyk (eds) Focus on first-year success: Perspectives from South Africa and beyond. Stellenbosch: Sun MeDIA. pp. 17-36.

Shohamy, E. 2006. Language policy: Hidden agendas and new approaches. London: Routledge.

Singh, M. 2009. On the way from the Forum: A future research agenda. In L. Meek, U. Teichler and M-L. Kearney (eds.) Higher education, research and innovation: Changing dynamics. Kassel: International Centre for Higher Education Research Kassel. Available online: http://ifap.ru/library/book431.pdf\#page=13. pp. 187-204.

Spolsky, B. 2004a. Language policy. Cambridge: Cambridge University Press.

Spolsky, B. 2004b. Language policy failures - why won't they listen? Series A: General and theoretical papers (584). Essen: LAUD. 
Tarrant, M. A. 2010. A conceptual framework for exploring the role of studies abroad in nurturing global citizenship. Journal of Studies in International Education 14(5): 433-451.

Tierney, W. 2008. The impact of culture on organisational decision making: Theory and practice in higher education. Sterling, VA: Stylus.

UNESCO Education Position Paper. 2004. Higher education in a globalized society. Paris: UNESCO. Available online: http://unesdoc.unesco.org/images/0013/001362/136247e.pdf.

Urban, E. and L. Palmer. 2014. International students as a resource for internationalization of higher education. Journal of Studies in International Education 18(4): 305-324.

Van der Walt, C., R. Mabule and J. De Beer. 2001. Letting the L1 in by the back door: Code switching and translation in Science, Mathematics and Biology classes. Journal for Language Teaching 35(2-3): 123-134.

Van der Walt, C. 2006. University students' attitudes towards and experiences of bilingual classrooms. Current Issues in Language Planning 7(2-3): 359-376.

Van der Walt, C. and J. Dornbrack. 2011. Academic biliteracy in South African higher education: Strategies and practices of successful students. Language, Culture and Curriculum 24(1): 89-104.

Van der Walt, C. 2013. Multilingual higher education: Beyond English medium orientations. Bristol: Multilingual Matters.

Van der Walt, C. and L. Hibbert. 2014. African languages in higher education: Lessons from practice and prospects for the future. In L. Hibbert and C. Van der Walt (eds.) Multilingual universities in South Africa. Bristol: Multilingual Matters. pp. 202-219.

Van Rooyen, B. 2005. The feasibility of simultaneous interpreting in university classrooms. Southern African Linguistics and Applied Language Studies 23(1): 81-90.

Williams, E. 2011. Language policy, politics and development in Africa. In H. Coleman (ed.) Dreams and realities: Developing countries and the English language. London: British Council. 41-57. 